\title{
Shallow Gas Prospect Evaluation in Shahbazpur Structure Using Seismic Attributes Analysis - a Case Study for Bhola Island, Southern Bangladesh
}

\author{
Morshedur Rahman, S. M. Mainul Kabir* and Janifar Hakim Lupin \\ Department of Geology, Dhaka University, Dhaka-1000, Bangladesh
}

(Received: 1 December 2015; Accepted: 31 March 2016)

\begin{abstract}
Shahbazpur structure is located in the southern Part of the central deep basin in the Hatia trough, where lie all the largest Gas fields of Bangladesh. A method is established to delineate the structural mapping precisely by interpreting four 2D seismic lines that are acquired over Shahbazpur structure. Moreover direct hydrocarbon indicators (DHI) related attributes are analyzed for further confirmation for presence of hydrocarbon. To do this synthetic seismogram generation, seismic to well tie, velocity modelling and depth conversion are performed. A limited number of seismic attributes functions that are available in an academic version of Petrel software are applied to analyze attributes. Seismic attribute analyses that are used in this interpretation mainly are associated to bright spot detection. Presence of bright spots or high amplitude anomaly over the present Shahbazpur structure, reservoir zone are observed. This signature will play a very important role in next well planning on the same structure to test the shallow accumulation of hydrocarbon. For better understanding of this shallow reserve, it is suggested to acquire 3D seismic data over Shahbazpur structure which will help to evaluate the hydrocarbon accumulation and to identify gas migration pathways.
\end{abstract}

Keywords: Shallow gas, Attribute analysis, Bright spot, Shahbazpur structure, Hatia trough.

\section{Introduction}

The Shahbazpur gas field in Bhola Island is one of the commercial gas fields of Bangladesh. The Shahbazpur structure is a subsurface anticlinal structure situated in the middle of the Bhola Island in the northern margin of Hatia trough of Bengal Foredeep. It is located in the southern part of Bangladesh and in the exploration Block no. 10. During field session ${ }^{12}$, Prakla Seismos carried out regional seismic survey on behalf of ARCO and confirmed the existence of a structure. To delineate the structure more precisely, BOGMC performed a detailed 12-fold digital seismic survey over the area in 1986-1987 field session by its own people. In search for the possibility of hydrocarbon occurrence in the Shahbazpur structure, an exploratory well was drilled by BAPEX ${ }^{4}$. It was then announced officially as a discovery of the gas field. 3 other wells were also drilled in the gas field. Shahbazpur well -2 is a vertical well which was drilled at a depth of $3485 \mathrm{~m}$. It is situated about $1 \mathrm{~km}$ North from Shahbazpur well-1. Another two wells also drilled within the half kilometer radius of Shahbazpur well $1\left(\right.$ Bapex $^{6}$. Both are directional wells and situated SE from Shahbazpur well -1. Shahbazpur well-3 was drilled at a depth of 3902m-MD (3502m-TVD) where Shahbazpur well4 has been drilled at a depth of $3805 \mathrm{~m}-\mathrm{MD}$ (3505m-TVD). From the depth of $2587 \mathrm{~m}$ to $3500 \mathrm{~m}$ (mKB-TVD) six gas zones are identified $\left(\right.$ Bapex $^{5)}$.

This study aims to depict the structural mapping precisely, analyze the DHI relevant attributes and provide an idea regarding future development planning in exploration point of view.

\section{Physical Setting}

The Shahbazpur gas field is located in Foredeep area of Bengal basin or can be said more precisely in the Hatia trough. The Foredeep part of the Bengal basin is located towards west from eastern fold belt where intensity of folds decreases continuously and Foredeep unit is characterized by only mild or no folding. So, the sedimentary layers are generally horizontal to sub horizontal and are free from major tectonic deformation in the Foredeep area $\left(\mathrm{Imam}^{8)}\right.$. This unit covers the central part of the basin and is represented by river to delta plain topography at the surface.

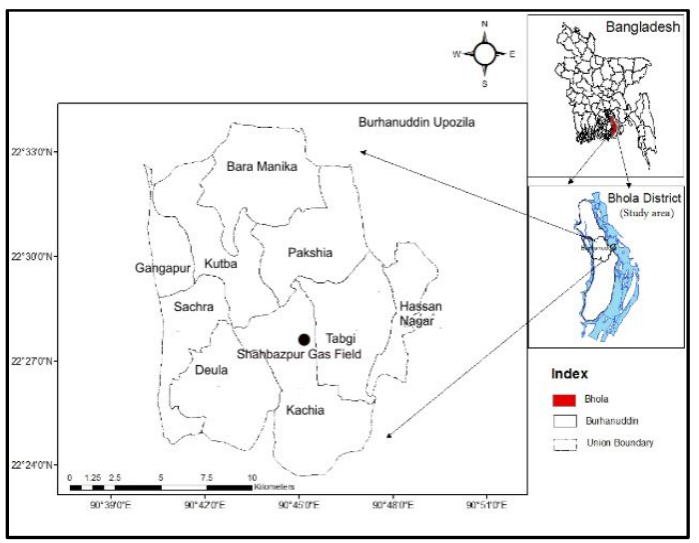

Fig.1. Location of Shahbazpur gas field $\left(\operatorname{Rahman}^{11}\right)$.

\section{Structural Framework}

The Shahbazpur structure is a subsurface anticlinal structure situated in the middle of the Bhola Island in the northern margin of Hatia trough of Bengal Foredeep. The Hatia trough is bounded by the Chandpur-Barisal high in the northwest, and by the Chittagong-Tripura Fold Belt in the southeast. The alignment of the NW-SE trending oval shaped Shahbazpur structure is parallel to the Kutubdia structure which is located in Bay of Bengal to the south. Shahbazpur Structure is surrounded by Muladi Structure to the Northwest and Kutubdia Structure to the Southeast (Fig.2). The structure started growing probably during Late Miocene and its acme of development took place during Mio-Pliocene sedimentation and ended in Pleisto-Pliocene time (Mondal et al. ${ }^{9}$ ). This structure is relatively $69.4 \mathrm{~m}$ higher than the Kutubdia structure. The amplitude of the structure increases with depth $\left(\right.$ Bapex $\left.^{5}\right)$. There is no surface expression of the Shahbazpur structure and the surface is floored with recent alluvial plain. 


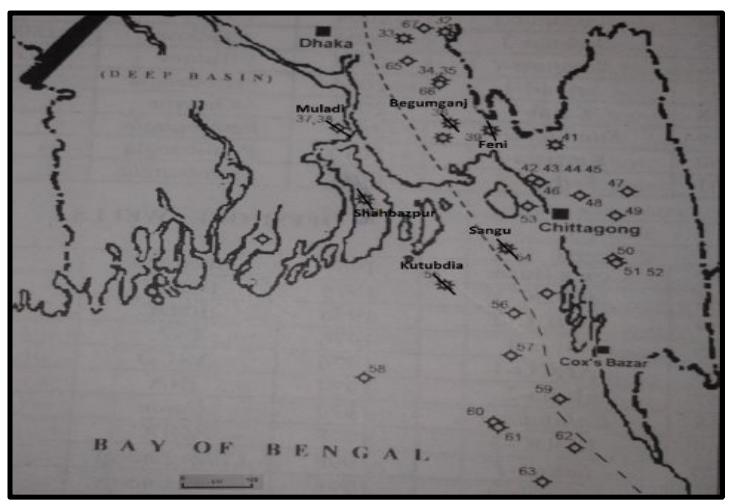

\section{Stratigraphy}

The Basin fill history of Foredeep is regressive in nature. That is it was build up by progressive sediments filling from deep sea to shallow marine to delta (tidal) and fluvial plain. The stratigraphic succession is thicker in the southern part of the region in the Faridpur and Hatia Troughs, but the stratigraphy is little known there (Alam et $\mathrm{al}^{1}$ ). The stratigraphy of the area was established with the help of systematic lithological description of the drilled section, log data and from seismic data, and from correlation with neighboring wells $\left(\right.$ Bapex $\left.^{5}\right)$. The stratigraphic succession is summarized in Table-1.

Fig. 2. Showing Shahbazpur structure with surrounding structures (modified after $\operatorname{Imam}^{8}$ ).

Table 1. Stratigraphy and lithology in the Shahbazpur structure (Modified after BAPEX ${ }^{5}$; Mondal et al $^{9}$ ).

\begin{tabular}{|c|c|c|c|c|c|}
\hline Depth (m) & Age & Group & Sequence $(\mathrm{m})$ & Lithology & $\begin{array}{l}\text { Depositional } \\
\text { Environment }\end{array}$ \\
\hline $0-480$ & Recent & & Alluvium (480) & $\begin{array}{c}\text { Loose unconsolidated } \\
\text { sand with occasional } \\
\text { clay }\end{array}$ & Fluvial Plain \\
\hline $480-1505$ & Pleistocene (?) & $\begin{array}{c}\text { Dupi Tila } \\
\text { (Tentative } \\
\text { assignment) }\end{array}$ & $\begin{array}{l}\text { SB sequence I } \\
\quad(1025)\end{array}$ & $\begin{array}{l}\text { Shale with occasional } \\
\text { occurrence of } \\
\text { interbedded sandstone } \\
\text { and calcareous siltstone }\end{array}$ & $\begin{array}{l}\text { Deltaic to Fluvial } \\
\text { plain }\end{array}$ \\
\hline $1505-2010$ & $\begin{array}{l}\text { Pleistocene- } \\
\text { Pliocene }\end{array}$ & Tipam & $\begin{array}{c}\text { SB sequence II } \\
(505)\end{array}$ & Shale and sandstone & \\
\hline $2010-2750$ & Plio-Miocene & Surma & $\begin{array}{c}\text { SB sequence III } \\
(740)\end{array}$ & Sandstone and shale & $\begin{array}{c}\text { Deep sea to } \\
\text { shallow marine }\end{array}$ \\
\hline $2750-3631$ & Miocene & & $\begin{array}{c}\text { SB sequence IV } \\
(881)\end{array}$ & Sandstone and shale & \\
\hline
\end{tabular}

\section{Available Data}

Data such as well log data, seismic line data and well completion report were collected from BAPEX, only which are available. The seismic data consists of four 2D multichannel seismic profiles covering part of the study area. All the $2 \mathrm{D}$ seismic line data acquired over the structure was not available. From the provided 2D seismic lines there are three dip lines and one strike line. All these surveys date back from the early 90 's. The spacing between one dip line to another dip line is about $2.5 \mathrm{~km}$.

Las files of well were also collected from BAPEX. Las files for two wells were provided and other two were not available. The Las file contains gamma ray log, sonic $\log$, resistivity $\log$, neutron porosity and density logs.

\section{Seismic Interpretation}

A total of five horizons have been interpreted using petrel software. The seismic troughs have been identified using well tops and are chosen from the well-defined section and are consistent over the area of interest. To ensure that, the seismic troughs correlate with the correct events as seen in well data, check shots and seismic sections have been utilized.

\section{Velocity modeling and depth conversion}

Depth conversion concerns the seismic interpreter because seismic measurements are made in time, but the wells based on a seismic interpretation are drilled in depth $\left(\right.$ Brown $\left.^{7}\right)$. To convert the time surface into a depth surface a velocity model has to be made because that's the parameter to relate time to depth. For this purpose, a T-Z curve or VSP (Vertical seismic profile) data is needed. For velocity modelling and synthetic generation $\mathrm{T}-\mathrm{Z}$ curve of Shahbazpur-2 well have been used. 


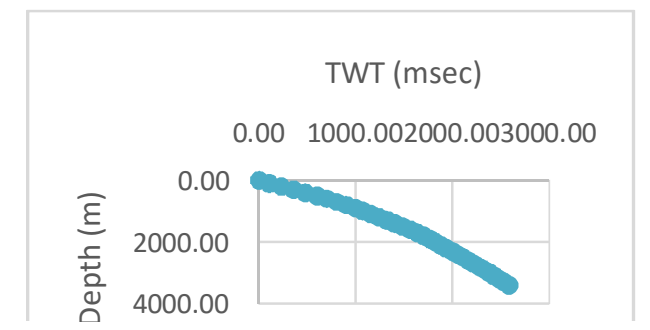

Fig. 3. T-Z curve used for seismic to well tie in Shahbazpur 2 well and velocity modeling $\left(\operatorname{Rahman}^{11}\right)$.

The well to seismic tie has been done using available timedepth relationships for SB-1 and SB-2 wells and sonic logs (Fig.4).

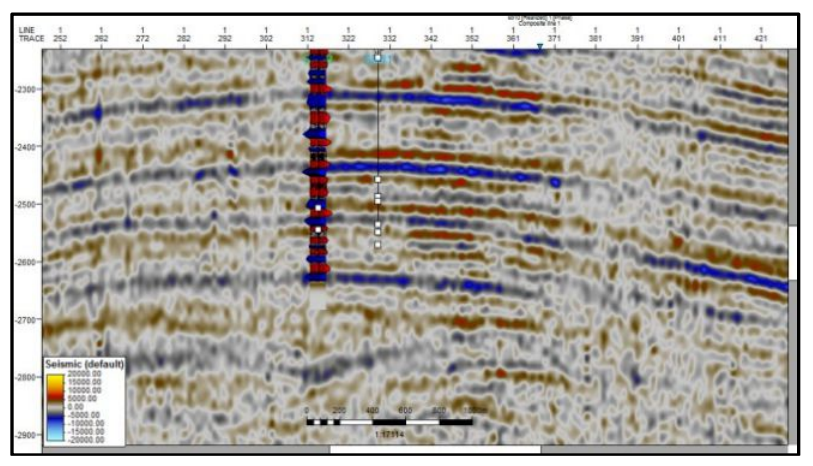

Fig. 4. Showing seismic to well tie between Shahbazpur-2 well and Sb-5 2D seismic line $\left(\operatorname{Rahman}^{11}\right)$

The resulted seismic to well tie gives low to moderate result, though some negative phase show good match. The result is moderate due to high sand shale alternation in the basin and moderate seismic resolution $(24 \mathrm{~m})$. But the seismic to well tie helped in picking tops of some gas zones. After the seismic to well tie and horizon picking, time surface has been generated. By using this time surface, well tops from Shabazpur well-1 and 2, and TDR (Time depth relation) from T-Z curve, a velocity model has been made (Fig.3), which later was used for depth conversion and to create depth surface.

\section{Structural interpretation}

Seismic interpretation shows that Shahbazpur structure is roughly an oval shaped anticline with simple four way dip closure which will be a good trap for hydrocarbon accumulation. There is no major fault system at the shallower part $(<2500 \mathrm{~m})$ though some minor fault and fracture have been observed $\left(\right.$ Bapex $\left.^{5}\right)$. A structural depth contour map has been produced by using top of the gas zone II (Fig.5).

\section{Attribute analysis}

Seismic attribute analysis used in this study is mostly related to bright spot identification in reservoir zones as well as to identify the similar response in both below and above the reservoir zones. Two seismic attributes that are available in petrel software are used for bright spot identification.

\section{RMS Amplitude}

"Root Mean Square" (RMS) amplitude is perhaps the most known attribute in the seismic world and by definition it is the "root mean square" of the original seismic trace amplitude. The RMS amplitude attribute is extracted from the seismic trace within a user-defined moving window with a width of $\mathrm{N}$ samples. This attribute gives information about the energy content of the seismic data.

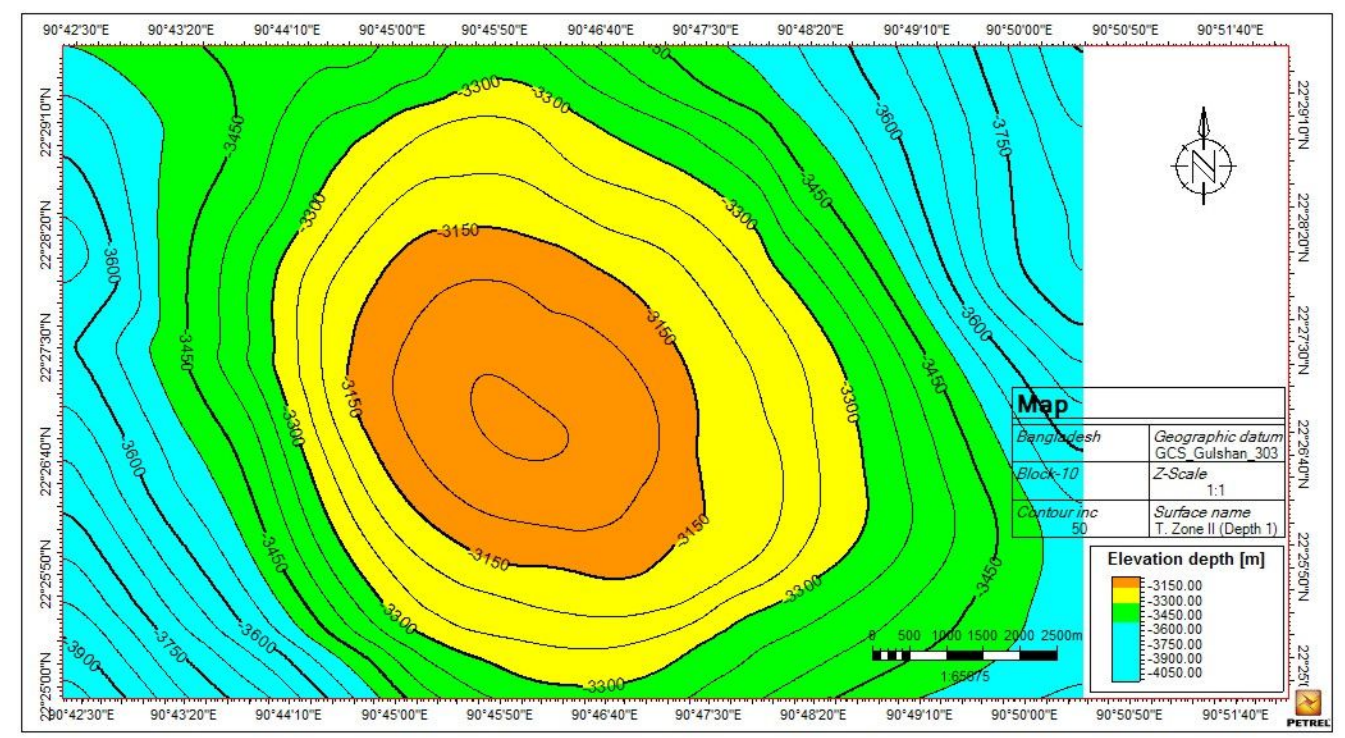

Fig. 5. Structural depth contour map of Shahbazpur structure $\left(\operatorname{Rahman}^{11}\right)$. 


$$
A_{R M S}(t)=\sqrt{\frac{1}{N} \sum_{k=-N / 2}^{N / 2}(f(t+k))^{2}}
$$

Typically, attributes related to the energy content of the seismic trace are used to distinguish different kinds of lithologies. High values of RMS amplitudes are commonly related to high porosity lithologies, such as porous sands, which are potential high quality hydrocarbon reservoirs $\left(\right.$ Petrel $\left.^{10}\right)$.

\section{Envelope (Reflection Strength)}

The envelope attribute, or Reflection Strength as designated by Taner et $\mathrm{al}^{13}$, was probably the first attribute calculated with Complex Trace Analysis. It is defined as the total instantaneous energy of the entire analytical trace, both real and imaginary parts.

$$
\operatorname{Env}=\sqrt{\mathrm{f}^{2}+\mathrm{g}^{2}}
$$

The $f$ and g are the "real" and "imaginary" components of the seismic trace. As an attribute is related to the energy content of the seismic trace, it is useful to detect major and subtle lithological changes that may be difficult to interpret from the original seismic input. High values of the envelope can appear due to major lithological changes and sedimentary sequence boundaries as well as are related to bright spots caused by gas accumulations. Gradual lateral changes of envelope values are often correlated with lateral variations in lithology (Taner et $\mathrm{al}^{13}$ ).

\section{Results and Discussions}

\section{Evidence for gas accumulation in SB Sequence-I unit of Dupi Tila Formation}

From the information of well tops it is known that the SB sequence-I unit has a depth range from $480 \mathrm{~m}-1505 \mathrm{~m}$. Time surface map and depth surface map of top of the SB sequence-I formation has been produced by algorithm available in petrel software. The depth surface of top of SB sequence-I (Fig.6) has same contour pattern like gas zone depth surface (Fig.5) but there is no closure in this unit.

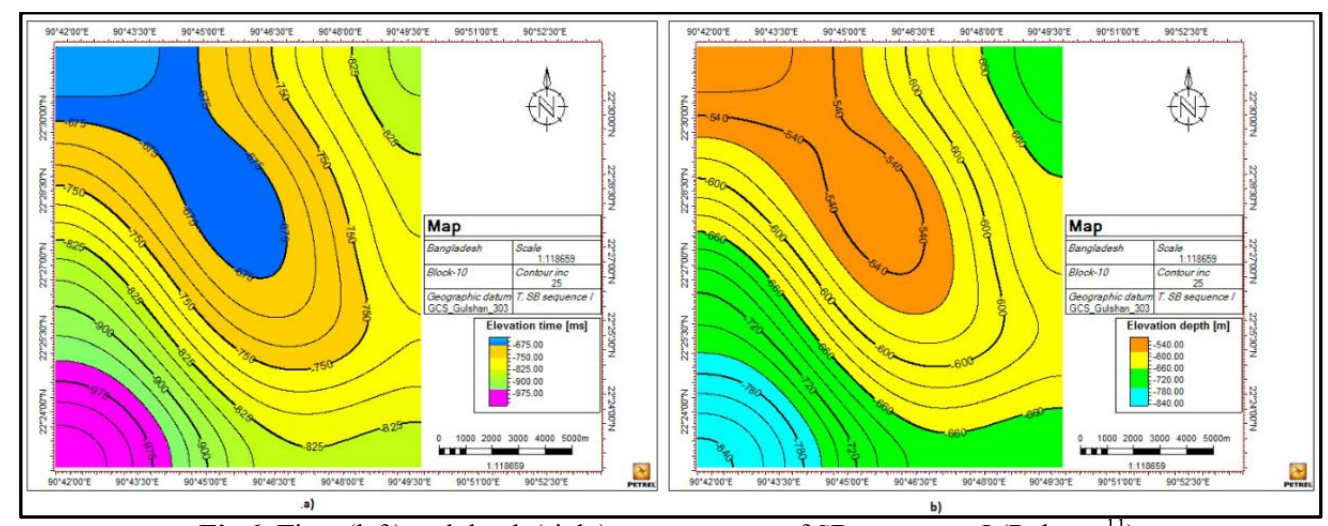

Fig.6. Time (left) and depth (right) contour maps of SB sequence- I (Rahman $\left.{ }^{11}\right)$.

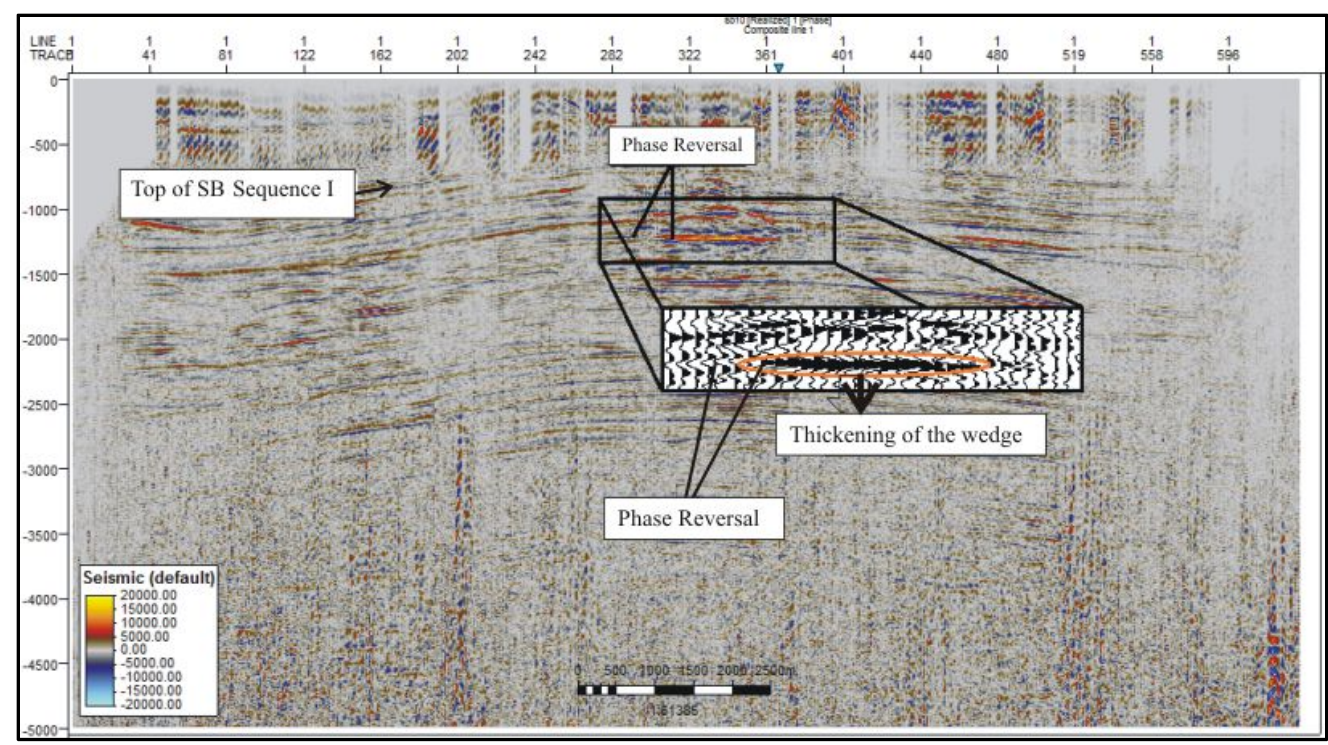

Fig. 7. Seismic indication of gas accumulation in SB sequence I (Rahman $\left.{ }^{11}\right)$. 
A strong reflection exists at the middle of the SB sequence-I due to an appreciable amount of acoustic impedance contrast. The high amplitude anomaly shows a reverse polarity and a distorted seismic pattern beneath it which is possibly due to gas accumulation (Fig.7). There may be a dramatic reduction of $\mathrm{V}_{\mathrm{p}}$ (P-wave velocity) in the gas accumulation zone which produces the anomalously high amplitude. This high amplitude anomaly is interpreted as a bright spot. The accumulation of gas can also be inferred from increasing thickness of the wedge. The TWT time where this strong reflection exists is $1250 \mathrm{~ms}$.

This strong reflection gives high RMS amplitude (Fig.8) which gives information about high amplitude anomaly. This strong reflection also gives high envelope value (Fig.9) which indicates the presence of high reflection strength. The high value of RMS amplitude commonly is related to high porosity lithologies, such as porous sands which are potential source for gas accumulation. The presence of gas at the depth of $1200 \mathrm{~m}-1250 \mathrm{~m}$ has been confirmed from mud $\log$ data $\left(\right.$ Bapex $\left.^{5}\right)$. The amount of gas present at this depth is about $2-3 \%\left(\right.$ Bapex $\left.^{5}\right)$.

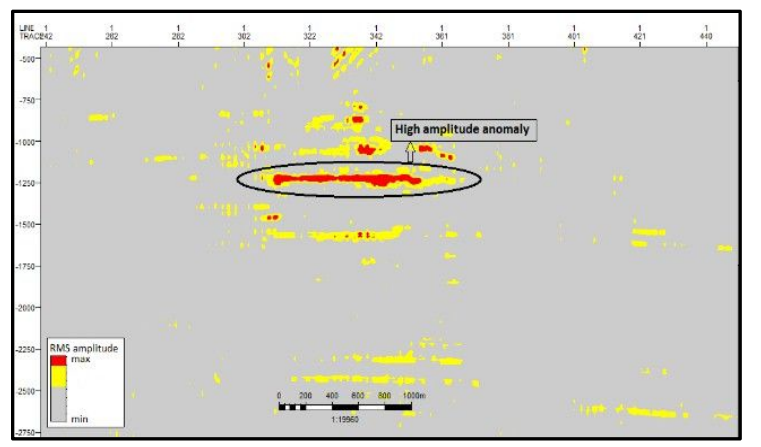

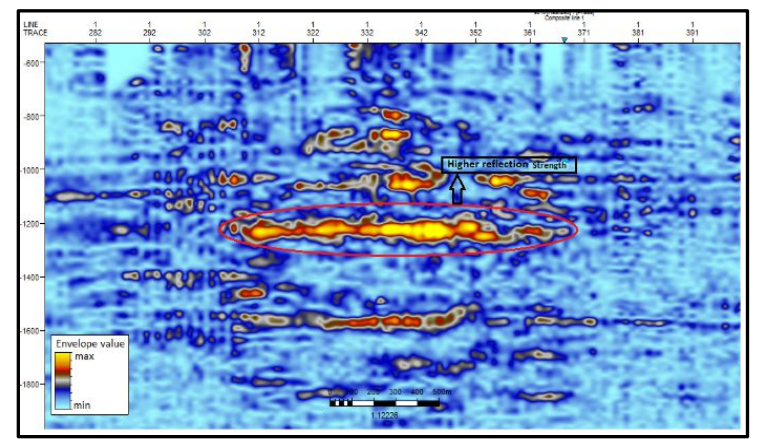

Fig. 9. Bright spot detected in SB sequence I by envelope attribute $\left(\right.$ Rahman $\left.^{11}\right)$.

\section{Evidence for gas accumulation in SB Sequence-II unit of Tipam Group}

The depth range of SB sequence-II unit is about $1505 \mathrm{~m}$ $2010 \mathrm{~m}$ which is taken from the well tops information. Time surface map and depth surface map of top of the SB sequence II unit has also been produced by algorithm available in petrel software. The depth surface of top of SB sequence-II (Fig.10) has same contour pattern like gas zone depth surface (Fig.5) but there is also no closure in this unit.

There is another strong reflection exists at the top of the SB sequence-II unit which also shows increasing thickness of the wedge. There is also a constructive interference that exists at the base of the strong reflector. Due to constructive interference the reflector has very high amplitude value which can be proved by observing the negative amplitude merged with the positive amplitude at the base (Fig.11).

Fig. 8. Bright spot detected in SB sequence I by RMS amplitude attribute $\left(\operatorname{Rahman}^{11}\right)$.

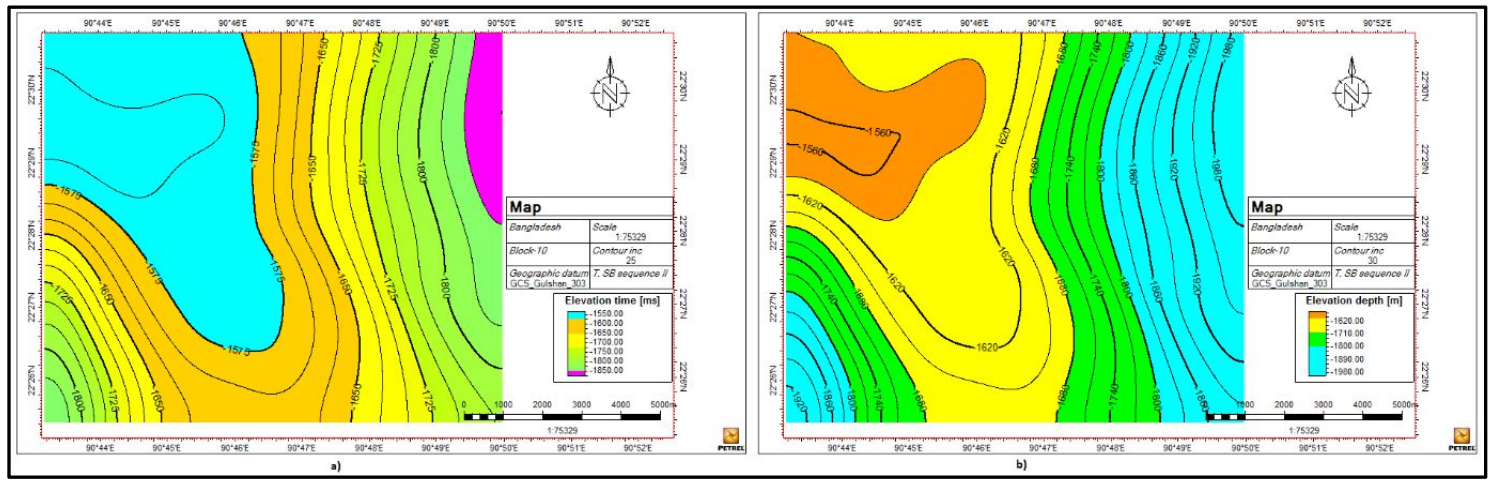

Fig. 10. Time (left) and depth (right) contour map of SB sequence-II (Rahman $\left.{ }^{11}\right)$.

This constructive interference may be occurred due to the presence of a low velocity zone in the interface which can indicate the presence of possible gas accumulation because presence of only small amount gas can reduces $V_{p}(P$ wave velocity) dramatically $\left(\operatorname{Rahman}^{11}\right)$. The low velocity of the gas zone causes a negative reflection coefficient at the top of the wedge and a positive reflection coefficient at the base of the wedge (Fig.11). This type of thinner gas accumulation can cause interference between reflections from the top and bottom of the reservoir (Andreassen et $\mathrm{al}^{2}$ ). The TWT time where this strong reflection exists is about $1575 \mathrm{~ms}$.

This strong reflection also gives high RMS amplitude (Fig.12) value and high envelope value (Fig.13) which confirms that it has high amplitude anomaly and higher reflection strength. Though other outcome cannot be neglected but assuming the above observation it can be said that the strong reflector is a bright spot which gives strong reflection due to presence of gas accumulation. 


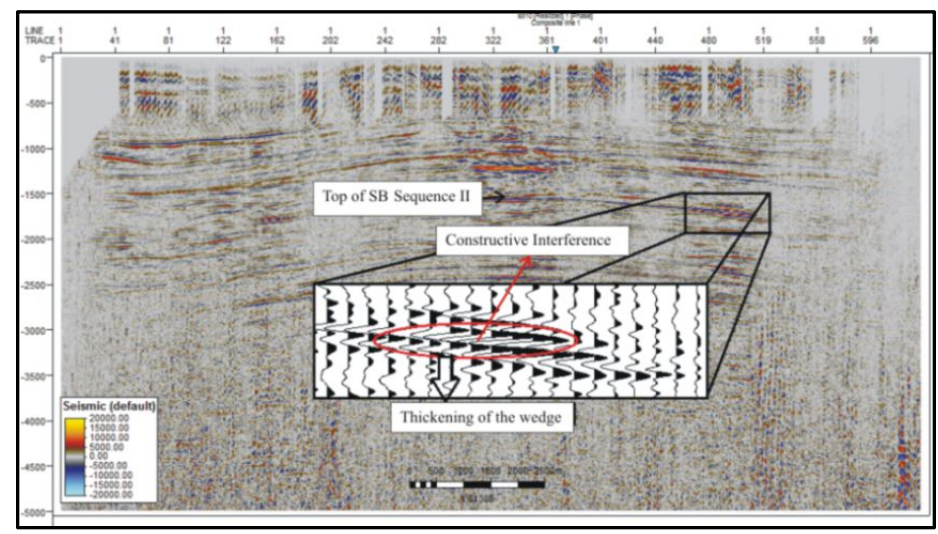

Fig. 11. Seismic indication of gas accumulation in SB sequence-II (Rahman ${ }^{11}$ ).

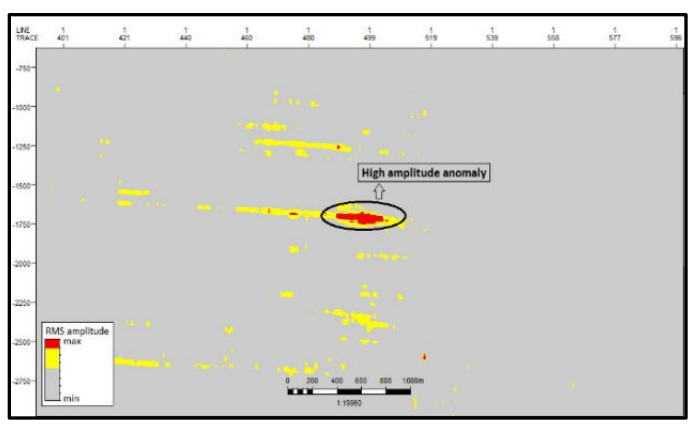

Fig. 12. Bright spot detected in SB sequence -II by RMS amplitude attribute (Rahman ${ }^{11}$ ).

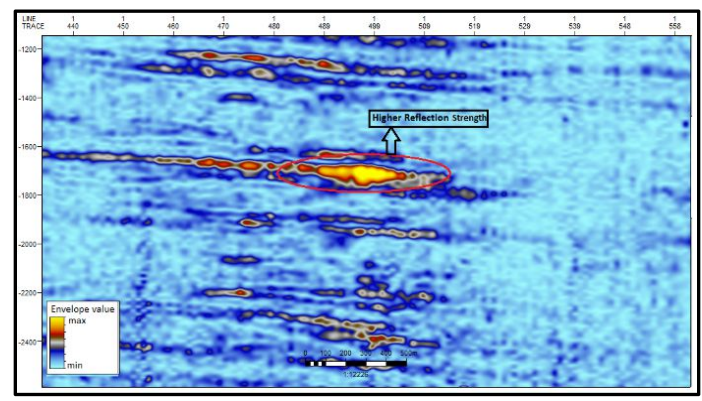

Fig. 13. Bright spot detected in SB sequence -II by envelope attribute (Rahman $\left.{ }^{11}\right)$.

\section{Conclusion}

Shahbazpur structure is an oval shaped NW-SE trending anticline which has a four way dip closure. It does not have any major fault system above gas horizons.

2D seismic attributes has its limitation and all bright spots doesn't indicate gas accumulation. Taking in consideration of possible interpretation pitfalls, attributes analysis suggest that bright spots exist in the shallower part of the structure above the present reservoir zones which might be a potential shallow gas reserve. The bright spots are located within Shahbazpur sequence-I of Dupi Tila Formation which is of Pleistocene age and Shahbazpur sequence-II of Tipam Group of Pleistocene-Pliocene age. High RMS amplitude and reflection strength in SB sequence-I of Dupi Tila Formation and SB sequence-II of Tipam Group suggests the presence of gas in moderate depth. Due to unavailability of 3D seismic data the evidence of migration pathway of gas cannot be determined. To know the source of the gas in SB sequence-I and SB sequence-II it is essential to know about migration pathway of gas of the area.

\section{Acknowledgement}

The authors are very thankful to Managing Director of Bangladesh Petroleum Exploration and Production Company Limited (BAPEX) for his support and giving the permission to use the data of BAPEX.

\section{Reference}

1. Alam, M., M. Alam, J. R. Curray, M. R. Chowdhury, and M. Gani, 2003. An overview of the sedimentary geology of the Bengal Basin in relation to the regional tectonic framework and basin-fill history: Sedimentary Geology, 155, 179-208.

2. Andreassen, K., E. G. Nilssen, and C. M. Ødegaard, 2007. Analysis of shallow gas and fluid migration within the PlioPleistocene sedimentary succession of the SW Barents Sea continental margin using 3D seismic data: Geo-Marine Letters, 27, 155-171.

3. ArcGIS (Geographic Information System) 102010 software.

4. Bapex Exploratory Drilling 1993 in Shahbazpur Structure.

5. Bapex; 1995 Geological interpretation of Shahbazpur Gas Field.

6. Bapex Additional Well Drilling (2014-15) in Shahbazpur Strucutre.

7. Brown, A. R., 2011. Interpretation of three-dimensional seismic data: Tulsa, Oklahoma., U. S. A., American Association of Petroleum Geologists.

8. Imam, B., 2013. Energy resources of Bangladesh: natural gas, oil, coal: Dhaka, University Grants Commission of Bangladesh.

9. Mondal, D. D., M. Islam, and A. Islam, 2009. Electrofacies Analysis of Neogene Sequence in the Well Shahbazpur-1, Bhola, Bengal Basin: The IUP Journal of Earth Sciences, 5.1, 57-74.

10. Petrel 64-bit 2013. from Schlumberger.

11. Rahman, M., 2015. Occurrence and Distribution of Shallow Gas in Southern Bangladesh: A Case Study on Bhola Island. M.S. Thesis, Department of Geology, University of Dhaka, Ramna, Dhaka (Unpubld.).

12. Regional Seismic Survey by Arco in 1974-75 Field Session.

13. Taner, M. T., F. Koehler, and R. E. Sheriff, 1979. Complex seismic trace analysis: Geophysics, 44. 6, 1041-1063. 
